\title{
Mass Casualty in A Building Collapse: Techniques of Anaesthesia in Mass Casualty Management (Rana Plaza Collapse at Savar, Bangladesh)
}

\author{
Hasan Murshed ${ }^{1}$, Atiqul Islam², Atiqul Hoque Sarder ${ }^{3}$
}

\author{
${ }^{1}$ Classified Specialist in Anaesthesia, CMH, Savar, ${ }^{2}$ Assistant Professor, Dept. of Anaesthesiology, Dhaka Medical College, \\ ${ }^{3}$ Graded Specialist in Surgery, CMH, Savar, Dhaka \\ Corresponding author: murshed673@yahoo.com
}

\begin{abstract}
:
Background: Management of mass casualties in a disaster like situation needs much of discussion. Proper planning and preparation can markedly change the mortality and morbidity following these events. Similarly right use of special skill of anesthesiologists in the management of mass casualty is of immense value.
\end{abstract}

Objectives: This study was aimed to investigate general injury profile, pattern of operations and anesthesia performed during mass casualty management of patients treated in the department of Anesthesia and Intensive care unit of Combined Military Hospitals, Savar.

Methods: This study retrospectively investigated the clinical records of 155 patient's files registered by many different doctors. We used discharge diagnosis, and when available objective $x$-ray or CT scan used for verification of fractures.

Results: Among 431 patients reported to emergency and casualty department, 407 (94.431\%) is admitted to hospital. Among 431 patients only 155 (35.962\%) is treated in the department of Anesthesia and Intensive care. Among 155 patients of ICU, most of the injuries were blunt trauma soft tissue, rest of the injuries were fractures, head injuries, crush injuries etc, which accounts 95 (61.29\%) patients. Majority of surgical procedure included wound debridment, fasciotomy, amputation and external fixation; constituted 51(33\%) patients. 132(84\%) surgical procedure performed under TIVA with ketamine, 22 (15\%) under different regional techniques and only one patient received general anesthesia.

Conclusion: Bangladesh is situated in a seismically active zone; fortunately no major earthquake has striken since 1940. Accelerated urbanization and high population densities in all cities are increasing the vulnerability of Bangladesh to catastrophic number of death and injuries. Ninety percent of casualties after earthquake result directly from the collapse of buildings in urban areas. The special skills of the anesthesiologist are of tremendous value in contributing mass casualty management in ICU and operating room. Our study concludes that surgical services can be maximized with the judicious and intelligent use of ketamine and regional anesthetic technique; rather than general anesthesia. Definitely it has strong value in maximizing use of scare resource in country like Bangladesh.

Keywords: mass casualty, ketamine, regional anesthesia

(JBSA 2014; 27(1): 12-16)

\section{Introduction}

Management of mass casualties in a disaster like situation needs much of discussion. ${ }^{1}$ Proper planning and preparation can markedly change the mortality and morbidity following these events. ${ }^{2}$ Similarly right use of special skill of anesthesiologists in the management of mass casualty is of immense value. The worst factory disaster in the country's history has occurred around 8:30am on $24^{\text {th }}$ April 2013. When a ninestoried commercial building "Rana Plaza" collapsed near Savar Bus Stand on the outskirts of the capital. According to official reports 1132 killed and 2438 injured in this disaster. This study was aimed 
to investigate general injury profile, pattern of operations and anesthesia given during mass casualty management of patients treated in the Department of Anesthesiology and Intensive Care unit of Combined Military Hospitals Savar.

\section{Methods}

This study was approved by our hospital authority. No informed consent was necessary as this study used existing data. This study retrospectively investigated the clinical records of 155 patients treated in the department of Anesthesiology and Intensive care unit with building collapse-related injuries during the 17 days that following 24th April 2013 "Rana Plaza Tragedy". This study retrospectively analyzed patient files registered by many different doctors. Systematically we used the discharge diagnosis, and when available we used objective x-ray or CT verification of fractures.

We used descriptive statistics to gain insight into general injury profile, pattern of operations and anesthesia given to injured patients admitted to this hospital after the building collapse.

\section{Results}

Maximum influx of injured patient were on $3^{\text {rd }}$ day of incident and 100\% reported patients were admitted from $4^{\text {th }}$ day onward (Fig-1). Among 431 patient reported to emergency and casualty department 407 (94.431\%) patient got admitted into hospital. Among 431patients only 155 (35.962\%) patient had been treated in ICU (Table-I). Most of the injuries were blunt trauma and soft tissue injury followed by fractures and crush injuries (Fig2).On the first day 16 operative procedure were performed (Table-II). Subsequently in average 22.5 operative procedures were performed daily on subsequent days. 49 major operative procedures were done under anesthesia in first 96 hour. Most of the major operative procedures were done under TIVA with Ketamine followed by regional technique; only one patient received balanced general anesthesia (Fig-3).

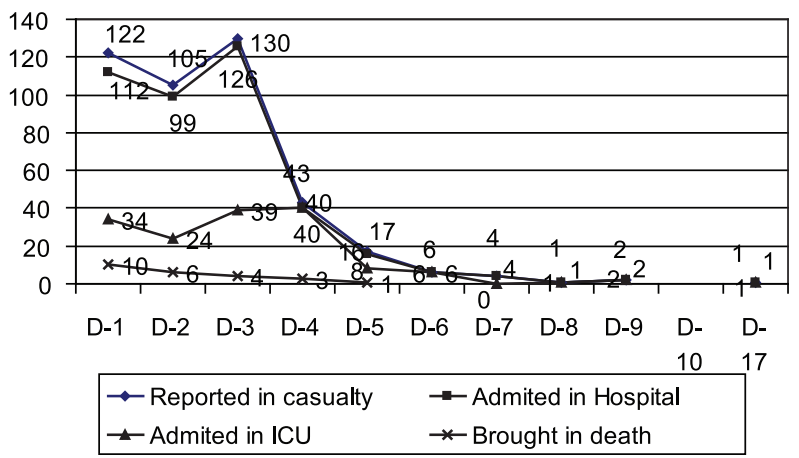

Fig 1 Distribution of Casualty Influx at Combined Military Hospital Savar:

Table I Patients Influx at Emergency Department and Admission in ICU ( $n=155)$

\begin{tabular}{lcccc}
\hline Day & $\begin{array}{c}\text { Reported at Emergency } \\
\text { and casualty dept; } \mathrm{n}\end{array}$ & $\begin{array}{c}\text { Admitted in } \\
\text { Hospital: } \mathrm{n}(\%)\end{array}$ & $\begin{array}{c}\text { Brought in } \\
\text { death: } \mathrm{n}\end{array}$ & $\begin{array}{c}\text { Treated in } \\
\text { ICU: } \mathrm{n}(\%)\end{array}$ \\
\hline 1. & 122 & $112(91.80)$ & 10 & $34(30.35)$ \\
2. & 105 & $99(94.28)$ & 06 & $24(24.24)$ \\
3. & $126(96.92)$ & 4 & $39(30.95)$ \\
4. & $40(93.02)$ & 3 & $40(100)$ \\
5. & $16(94.11)$ & 1 & $08(50)$ \\
6. & 130 & $06(100)$ & - & $06(100)$ \\
7. & $04(100)$ & - & 00 \\
8. & $01(100)$ & - & $01(100)$ \\
9. & 06 & $02(100)$ & Nil & $02(100)$ \\
10 to 16 & 04 & Nil & - & Nil \\
17. & 01 & $01(100)$ & 24 & $01(100)$ \\
\hline Total & 02 & $407(94.43)$ & & $155(38.08)$ \\
\hline
\end{tabular}


Table II Surgical Operative Procedure Done at Combined Military Hospital Savar

\begin{tabular}{|c|c|c|c|c|c|c|}
\hline \multirow[t]{2}{*}{$\overline{\text { Day }}$} & \multicolumn{6}{|c|}{ Operative procedure } \\
\hline & $\begin{array}{r}\text { Major } \\
\text { Fasciotomy }\end{array}$ & $\begin{array}{l}\text { rocedure } \\
\text { Amputation }\end{array}$ & $\begin{array}{c}\text { Wound } \\
\text { debridment }\end{array}$ & $\begin{array}{c}\text { External fixation } \\
\text { of fracture }\end{array}$ & $\begin{array}{c}\text { Minor } \\
\text { Dressing } \\
\text { and/ POP }\end{array}$ & Total \\
\hline One & 1 & - & 6 & - & 9 & 16 \\
\hline Two & 5 & 1 & 9 & 1 & 14 & 30 \\
\hline Three & 3 & 1 & 6 & - & 10 & 20 \\
\hline Four & 6 & 1 & 8 & 1 & 6 & 22 \\
\hline Five & - & - & 2 & - & - & 2 \\
\hline Six & - & - & - & - & 35 & 35 \\
\hline Seven & - & - & - & - & 26 & 26 \\
\hline Total & 15 & 3 & 31 & 2 & 100 & 151 \\
\hline
\end{tabular}

Table III Anesthetic Procedures Followed in Different Surgical Procedure:

\begin{tabular}{lcccccc}
\hline Type of Anesthesia & $\begin{array}{c}\text { Major procedure } \\
\text { Fasciotomy }\end{array}$ & Amputation & $\begin{array}{c}\text { Wound } \\
\text { Debridment }\end{array}$ & $\begin{array}{c}\text { Minor } \\
\text { Fixternal } \\
\text { Fressing/ } \\
\text { POP }\end{array}$ & Total \\
\hline Subarachnoid Block & 3 & 1 & 1 & 1 & - & 06 \\
Brachial plexus block & 2 & 2 & 3 & - & - & 07 \\
Femoral nerve block & 4 & - & - & - & - & 04 \\
Commn peroneal nerve block & 3 & - & - & - & - & 03 \\
Ankle block & 2 & - & - & - & - & 02 \\
General Anesthesia & - & - & 1 & - & - & 01 \\
TIVA with LA & 1 & - & 26 & 1 & 104 & 132 \\
\hline Total & 15 & 3 & 31 & 2 & 104 & 155 \\
\hline
\end{tabular}

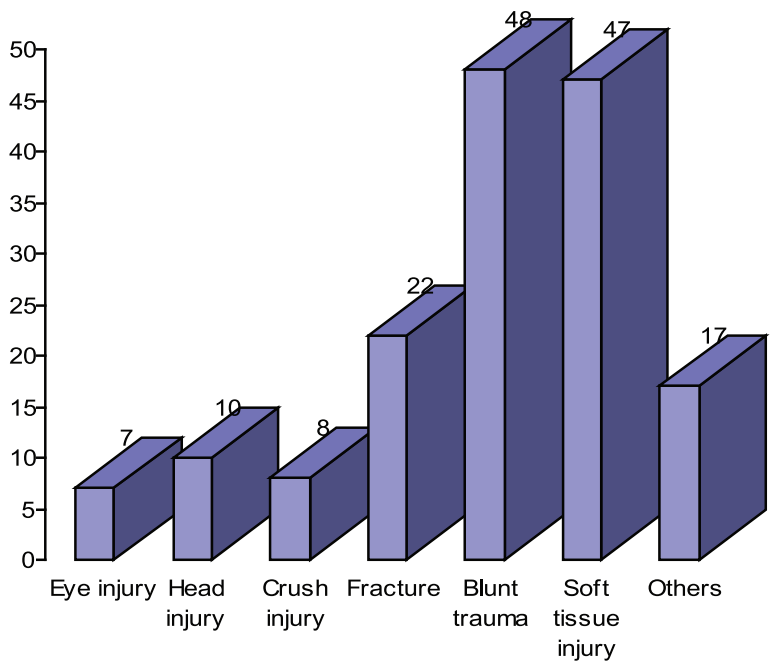

Fig 2 Pattern of Injuries Treated in ICU at Combined Military Hospital, Savar:

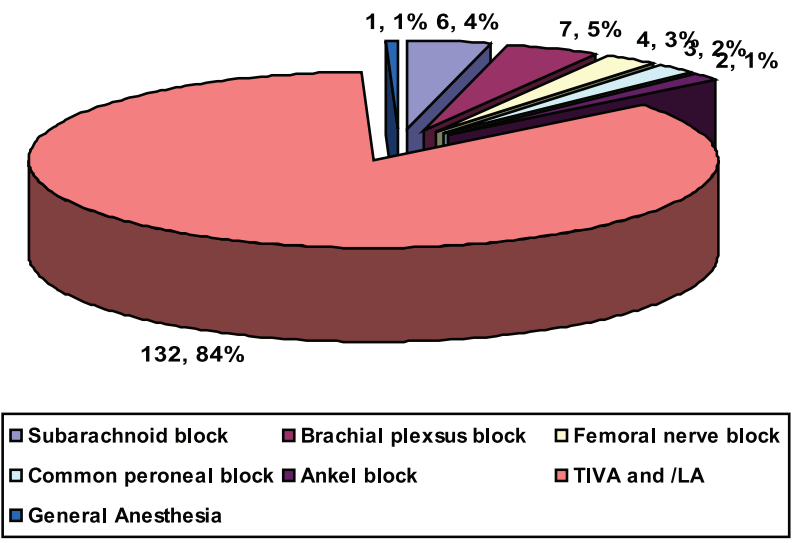

Fig 3 Pattern of Anesthetic Procedures Followed in Different Surgical Procedure: 


\section{Discussion}

What is the burden and distribution of surgical conditions after building collapse? Study on isolated building collapse is very few. Different study showed ninety percent of casualties after earthquake result directly from the collapse of buildings in urban areas. ${ }^{3}$ So distribution of surgical condition following earthquake is likely to simulate picture of building collapse.

There were two waves of casualties in Rana plaza tragedy. The first wave represented by the "walking wounded". These include a large number of people who have been hurt by falling objects or victims trapped by light debris and who have been promptly rescued by their family members and neighbors. First wave of casualty in any mass casualty event usually occur during first few hours of incident. Which is managed by nearby hospitals as most of them are "walking wounded"; "Rana Plaza Tragedy" is also not of this exception. Large numbers of first wave patients were treated by nearby hospitals. Our study also shows majority of patient brought to our casualty department were within first three days of incident (Fig-1). Our hospital is approximately seven kilometer from the incident place. Thus most of the casualty transported by military and civil ambulance till third day, because nearby hospital and private clinic were flooded with patients. The second wave of casualties includes those who were buried deeply under structural debris. The primary concern with the second wave was the complexity of their medical treatment and not their numbers; these casualties were rescued one-by-one. Our study shows third day onward the number of casualty were decreased but needing ICU support was 100\% of reported patients (Table-I). Among casualties not all, only one fourth patients' needed ICU support, indicating large number of casualty are not critical (Table-I).

Research following the 1988 earthquake in Armenia showed that superficial injuries are accounted for the majority of the cases. ${ }^{4}$ This was supported by findings of earlier studies also. ${ }^{5,6}$ Sixty percent of our casualty had also blunt trauma and soft tissue injuries, which is consistent with previous study. A number of studies also emphasized the importance of crush injury and fractures following building collapse, which often represent more than half of the recorded injuries. ${ }^{7,8,9}$ But only $19 \%$ of our casualty had crush injuries and fracture, which is not consistent with previous study, as because all casualty of Rana Plaza tragedy did not reported to our hospital, some reported in other nearby private hospital.

Significant number of our patient had trauma in limbs, although some patients were with altered consciousness but operative procedure could be managed by regional techniques. Especially limb fasciotomy, which under subachnouid block is impractical due to haemodynamic instability in mass casualty due to associated trauma. Most of our patient's fasciotomy done by brachial plexsus block, femoral nerve block, common peroneal nerve block, ankle block (Table- III). Thus by doing large number of faciotomy we could save good number of limbs.

In our mass casualty management we needed to limit operative intervention in specific but essential procedures. Because we had no posted orthopedic surgeon, neurosurgeon, moreover we had only one ICU ventilator. Where appropriate, most of our operative procedures for superficial and blunt trauma were done under TIVA with ketamine.

In 1959 for search of a safe but potent sedative agent led pharmacologists to the phencyclidines and Ketamine. Ketamine was introduced into clinical practice in 1970 during Vietnam War. With the administration of Ketamine the patient goes into a trance like state. He becomes unconscious, amnestic and deeply analgesic. His airway is remarkably preserved. Thus Ketamine is especially useful if there is no recovery ward and there is lack of trained anesthetists. ${ }^{10}$ This drug is remarkably safe but not absolutely safe, so one has to be vigilant. It is ideal for use in emergency cases in which patients are in mild to moderate shock. ${ }^{11}$ Ketamine also useful during minor procedures, such as in wound debridement and painful dressing. In lower doses it is useful for brief emergency procedures. ${ }^{12}$ Eighty four percent of our patients received TIVA with ketamine for surgical procedure and recovery were uneventful (Fig-3). So ketamine remains as choice of drug in mass casualty management where it is appropriate. This strengthens the role of ketamine in any mass casualty in our country, where there is scarcity of trained anesthesiologist. 
Subarachnoid block (SAB) which is usually impractical in mass casualty patients with life threatening injuries. Among regional anaesthetic techniques mostly followed in our mass casualty management were brachial plexsus block, peroneal nerve block, and ankle block etc. This allowed us to accomplish large number of surgical procedure with life threatening injuries. (Fig-3) There was only one death following surgical intervention, during 'Rana Plaza Tragedy". These highlight the importance of regional anesthetic technique that is used mostly in our mass casualty management. Unfortunately practice of different regional techniques among anesthesiologist is very less. But learning these techniques is of immense help in mass casualty patient management.

We had limitation of study also that include all head injured patient with or without associated other trauma were referred immediately to different hospital for definitive treatment.

Most of our surgical operative procedure were done under TIVA (Ketamine) and or LA, rest by regional technique. Only one patient received general anesthesia. It signifies importance of learning different regional anesthetic procedure among anesthesiologist. Thus more emphasis needed to teach on regional anesthetic techniques among trainee anesthesiologist and intensive care expert, when possible with ultrasound guided techniques, which is widely practice in developed world. Moreover surgical services can be maximized with the judicious and intelligent use of ketamine and regional anesthetic technique; rather than general anesthesia.

\section{Conclusion}

Bangladesh is situated in a seismically active zone; fortunately no major earthquake has striken since 1940. Accelerated urbanization and high population densities in all cite are increasing the vulnerability of Bangladesh to catastrophic number of death and injuries should an earthquake strike the country. Incidents of infrastructure collapse are on the rise. So prevention and preparedness program are absolute necessity of the time. The special skills of the anesthesiologist make his/her contribution to mass casualty management as well in ICU and operating room particularly valuable. Our study concludes that surgical services can be maximized with the judicious and intelligent use of ketamine and regional anesthetic technique; rather than general anesthesia. Definitely it has strong value in maximizing use of scare resource in country like Bangladesh.

\section{References:}

1. Cuny FC. Principles of disaster management. Lesson 1: Introduction. Prehospital Disaster. Med 1998; 13: 88-93.

2 Clifford G. Pain Management in Mass Casualty Incidents. ITACCS Winter 2004; 27-28.

3. Ashkenazi I, Isakovich B, Kluger Y, Alfici R, Kessel B, Better OS. Prehospital management of earthquake casualties buried under rubble. Prehosp Disast Med 2005; 20:122-133.

4. Noji EK. The Public Health Consequences of Disasters New York: Oxford University Press; 1997.

5. Glass RI, Urrutia JJ, Sibony S, Smith H, Garcia B, Rizzo L. Earthquake injuries related to housing in a guatemalan village. Science 1977; 197:638-643.

6. Bruycker M, Greco D, Lechat MF. The 1980 earthquake in Southern Italy-morbidity and mortality. Int J Epidemiol 1985; 14:113-117.

7. Kuwagata Y, Oda J, Tanaka H, et. al. Analysis of 2,702 traumatized patients in the 1995 Hanshin-Awaji earthquake. J Trauma 1997; 43:427-432.

8. Peek-Asa C, Kraus JF, Bourque LB, Vimalachandra D, Yu J, Abrams J. Fatal and hospitalized injuries resulting from the 1994 Northridge earthquake. Int J Epidemiol 1998; 27:459-465.

9. Bulut M, Fedakar R, Akkose S, Akgoz S, Ozguc $H$, Tokyay R. Medical experience of a university hospital in Turkey after the 1999 Marmara earthquake. Emerg Med J 2005; 22:494-498.

10. ASA: Practice guidelines for sedation and analgesia by non- anesthesiologists. A report by the American Society of Anesthesiologists Task Force on Sedation and Analgesia by NonAnesthesiologists. Anaes 1996; 84: 459-471.

11. Bhattacharya A, Gurnani A, Sharma PK, Sethi AK: Subcutaneous infusion of ketamine and morphine for relief of postoperative pain: a double-blind comparative study. Ann Acad Med Singapore 1994; 23: 456-459.

12. Fallen MT, Welsh J. The role of ketamine in pain control. Eur J Palliation 1996; 3: 143146. 